\title{
Interaction of phonetics, phonology, and sociophonology - illustrated by the vowels of Standard Austrian German
}

Sylvia Moosmüller

Acoustics Research Institute, Austrian Academy of Sciences, Austria

https://doi.org/10.36505/ExLing-2008/02/0044/000103

\begin{abstract}
Standard Austrian German, which distinguishes eight front vowels, exploits two front constriction locations for distinguishing these vowels, a pre-palatal and a palatal one. However, the pre-palatal location is acoustically unstable, and, consequently, phonologically undesirable. The existence of a sound change which neutralizes the /i/ and /I/ vowels in a first step and shifts the constriction location of the remaining /i/ towards the palatal region in a second step is investigated.
\end{abstract}

Keywords: phonetics-phonology interface, vowels, sound change

\section{Introduction}

All vowels are articulated at a specific constriction location. Stevens (2003) argues that regions of acoustic stability are separated by regions of acoustic instability, and these natural boundaries define the opposition between distinctive features. In Steven's quantal theory (1989), vowel phonemes have an acoustic basis.

Wood $(1979,1982)$ isolated four contrastive constriction locations for vowels: "along the hard palate, along the soft palate, in the upper pharynx and in the lower pharynx" (1982: 43). Stevens (1989) found three zones - a palatal, a velar, and a pharyngeal zone -, where vowels spectra are relatively insensitive to small displacements in constriction location. For acoustic reasons, the velar and upper pharyngeal constriction are unified by Stevens.

Some languages, however, make use of a further constriction location in the front region. Fant $(1970,2001)$ describes a pre-palatal constriction location for Swedish and Russian, Wood (1979) for Egypt, Eek and Meister (1994) for Estonian, and Tabain and Perrier (2005) for French. Standard Austrian German (SAG) is a further language which exploits the pre-palatal constriction location (Moosmüller 2007).

Acoustically, the pre-palatal constriction location in /i/ is identified by a substantial rise of F3 due to a switch in the cavity affiliation of F2 and F3 (Stevens 1999). However, this region is acoustically unstable; a widening of the constriction degree or a shortening of the constriction length immediately leads to a lowering of F3.

ExLing 2008: Proceedings of 2nd Tutorial and Research Workshop on Experimental Linguistics, 25-27 August 2008, Athens, Greece 
Phonologically, an acoustically unstable constriction location is undesirable. Therefore, there is a preference to articulate the front vowels at the more stable palatal location. However, in order to shift the four pre-palatal vowels of SAG to the palatal location, it is necessary to reduce the number of front vowels. Consequently, as a pre-requisite to such a shift, the two /i/vowels and the two $/ y /$-vowels, each pair distinguished by constriction degree, have to be neutralised. This results in a sound change. The following questions arise:

1. Can the pre-palatal constriction location be proved for all speakers?

2. Does a neutralisation of the $/ \mathrm{i} /$-vowels and $/ \mathrm{y} /$-vowels take place in SAG?

3 Can a shift towards the palatal constriction location be observed?

\section{Method}

Ten speakers (five male, five female), aged from 18 to 84, were asked to read a list of sentences, repeat sentences, and speak spontaneously. The subjects were raised in Vienna with at least one parent raised in Vienna as well ${ }^{1}$. The elder subjects have an academic training, the younger ones are either students or have been to a grammar school.

For the current investigation, all /i/, /I/, and /e/-vowels ${ }^{2}$ in stressed position (539 in total) of the spontaneous speech task were segmented manually. F1, F2, and F3 were extracted by means of LPC. A 46 ms long gliding Hanning window was applied with an overlap of 95\%. Duration and F0 were measured as well. Depending on the duration of the vowel, the measurement procedure described rendered 20 to 150 measurements per vowel, i.e., the formant frequency contour of the whole vowel was analysed. This method was chosen because vowels, especially when short, often expose no steady state portion.

For statistical analysis, one-tailed t-tests were performed.

\section{Results}

\section{The pre-palatal constriction location}

Looking at the unrounded, constricted vowels, it was observed that the F3/F2 ratio is higher for the pre-palatal vowels than for the palatal vowels. Calculated at the highest point of F3, the F3/F2 ratio of a typical pre-palatal /i/ is $>1.4$. In order to account for a shortening of constriction length in spontaneous speech, the threshold of the ratio is lowered to $>1.3$. 
Table 1. Frequency (in \%) of F3/F2 ratios of the vowel /i/ in stressed position, spontaneous speech.

\begin{tabular}{|c|c|c|c|}
\hline Speaker & Year of birth & $\mathrm{F} 3 / \mathrm{F} 2>1.3$ & $\mathrm{~F} 3 / \mathrm{F} 2>1.4$ \\
\hline HK 0 & 1923 & 30.00 & 3.33 \\
\hline FK 9 & 1924 & 7.69 & 0.00 \\
\hline $\mathrm{BE}$ 오 & 1953 & 57.14 & 7.14 \\
\hline $\mathrm{AS} \mathrm{O}^{\lambda}$ & 1956 & 52.17 & 21.74 \\
\hline $\mathrm{UD}+$ & 1963 & 9.09 & 0.00 \\
\hline FN $0^{\lambda}$ & 1966 & 69.23 & 7.69 \\
\hline $\mathrm{CL}+$ & 1976 & 52.17 & 13.04 \\
\hline $\mathrm{EB}$ ㅇ & 1982 & 7.69 & 0.00 \\
\hline FM $\hat{0}$ & 1982 & 5.56 & 0.00 \\
\hline LH Ō & 1989 & 40.54 & 8.12 \\
\hline
\end{tabular}

It becomes evident from Table 1 that seven speakers (HK, BE, AS, FN, CL, EB, LX) exploit the pre-palatal constriction location for the vowel $/ \mathrm{i} /$. For the remaining speakers (FK, UD, FM), the results remain unclear, since they exhibit no F3/F2 ratios $>1.4$. Their results have to be evaluated in conjunction with the results for the vowels $/ \mathrm{i} / \mathrm{-} / \mathrm{e} /$. Most interestingly, however, no generation-specific dependence of F3/F2 ratios can be found.

It might be argued that the ratio depends on the duration of the vowel, i.e., the longer the vowel, the higher the F3/F2 ratio. However, only one speaker (FM) shows a statistically significant correlation between vowel duration and $\mathrm{F} 3 / \mathrm{F} 2$ ratio $(\mathrm{r}=0.81, \mathrm{p}<0.01)$.

\section{Neutralisation of the pair /i/ and /I/}

Six speakers (HK, UD, FN, CL, EB, FM) neutralise the opposition between /i/ and /I/, whereby /I/ adapts to /i/. FK and BE still distinguish the pair via all three formants, whereas AS distinguishes the pair only via F1, and LH, the youngest speaker, by F2. Despite the fact that these result again do not exactly fit the hypothesis of a generation-specific variation, the assumption of a sound change in progress is nevertheless supported.

\section{The vowels /i/ and /e/}

A shift of /i/ to the palatal constriction location might lead - temporarily - to a neutralisation of /i/ and /e/ with respect to F3, until a new, wider constricttion degree is settled for /e/. Only one speaker (FM) shows such a neutralisation, in conjunction with a higher F2 for /i/. The other two speakers who had low F3/F2 ratios (FK, UD) distinguish /i/ and /e/ for F3. Therefore, it can be assumed, that only speaker FM has shifted the vowel /i/ to the palatal location. 


\section{Conclusion}

The results presented in this paper strongly point to a current sound change. However, only the first step - the neutralisation of /i/ and /I/ - could be proved. The second step, the shift towards the palatal location, has yet to be accomplished. It may very well be that this step will not take place at all, since phonology is not the only motivation for the neutralisation of $/ \mathrm{i} /$ and /I/. The Middle Bavarian dialects, which strongly interact with SAG, distinguish vowel pairs by duration. It is of interest that three out of the six speakers who neutralise /i/ and/I/ for quality, distinguish these vowels by duration. Therefore, the adaptation of /I/ to /i/ might, additionally, be motivated by social factors.

\section{Notes}

1 Vienna was chosen for practical reasons, SAG is defined in Moosmüller (1991).

2 The /y/, /Y/, and /ø/-vowels have not been analysed, because they make up only $1 \%$ of all vowel occurrences (see Moosmüller 2007). The analysis of the vowel /e/ is necessary in order to evaluate the results of $/ \mathrm{i} /$.

\section{References}

Fant, G. 1970. Acoustic Theory of Speech Production. The Hague, Mouton.

Fant, G. 2001. Swedish vowels and a new three-parameter model. THM-QPSR $1 / 2001,43-49$.

Eek, A. and Meister, E. 1994. Acoustics and perception of Estonian vowel types. PERILUS XVIII, 55-90.

Moosmüller, S. 1991. Hochsprache und Dialekt in Österreich. Wien, Böhlau.

Moosmüller, S. 2007. Vowels in Standard Austrian German. Habil.-Schrift, Wien.

Stevens, K. 1989. On the quantal nature of speech. Journal of Phonetics 17, 3-46.

Stevens, K. 1999. Acoustic Phonetics. Cambridge Mass., MIT Press.

Stevens, K. 2003. Acoustic and Perceptual Evidence for Universal Phonological Features. In Proc. of the 15th Intern. Congress on Phonetic Sciences, vol. 1, 3338, Barcelona, Spain.

Tabain, M. and Perrier, P. 2005. Articulation and acoustics of /i/ in preboundary position in French. Journal of Phonetics 33, 77-100.

Wood, S. 1979. A radiographic analysis of constriction location for vowels. Journal of Phonetics 7, 25-43.

Wood, S. 1982. X-Ray and Model Studies of Vowel Articulation. Lund Working Papers 23. 